\title{
KEDINAMISAN DALAM KEARIFAN LOKAL: PERANCANGAN IDENTITAS VISUAL GALERI SULAM PINJAIK PATAH
}

\author{
Erni Masdupi ${ }^{1}$, Tri Kurniawati ${ }^{2}$, Halkadri Fitra ${ }^{3}$, Dini Faisal ${ }^{4}$ \\ ${ }^{1}$ Manajemen, Fakultas Ekonomi, Universitas Negeri Padang \\ ${ }^{2}$ Pendidikan Ekonomi, Fakultas Ekonomi, Universitas Negeri Padang \\ ${ }^{3}$ Akuntansi, Fakultas Ekonomi, Universitas Negeri Padang \\ ${ }^{4}$ Desain Komunikasi Visual, Fakultas Bahasa dan seni, Universitas Negeri Padang \\ emasdupi@fe.unp.ac.id ${ }^{1}$, trikurniawati@fe.unp.ac.id ${ }^{2}$, halkadri@fe.unp.ac.id ${ }^{3}$, dinifaisal@fbs.unp.ac.id ${ }^{4}$
}

\begin{abstract}
Abstrak
Galeri Sulam Pinjaik Patah sebagai usaha kolektif warga Nagari Panampuang memiliki potensi menjadi salah satu ikon produk sulam di Sumatra Barat. Namun, dari sisi desain grafisnya belum memiliki solusi desain yang baik. Logo yang dimiliki belum dapat memperkenalkan karakter, kepribadian, dan ciri khas Sulam Pinjaik Patah. Identitas visual merupakan jawaban bagi permasalahan Galeri Sulam Pinjaik Patah karena penggunaan identitas visual yang sistematis, terstruktur dan konsisten akan mampu membangun brand awareness. Identitas visual dirancang dengan menggunakan metode research and development (R\&D) yang terdiri dari tahapan mengenali potensi dan masalah, merancang desain produk, validasi dan uji coba. Hasil rancangan identitas visual memiliki elemen yang dinamis, aplikasi yang fleksibel sehingga memberi ruang bagi entitas untuk mengembangkan elemen dari identitas visual.
\end{abstract}

Kata kunci: galeri sulam, identitas visual, kearifan lokal, pinjaik patah

\begin{abstract}
Galeri Sulam Pinjaik Patah has the potential of becoming one of the icons of embroidery products in West Sumatra. However, the gallery does not have a better graphic design solution. Its current logo does not introduce the character, personality, and characteristics of the origin of the name Pinjaik Patah embroidery. The problem is gallery needs more recognition to create brand awareness. It demands a systematic and consistent use of visual identity, not just a logo. The research and development (R\&D) method is used to design the visual identity. The stages are identifying potentials and problems, designing product designs, validating, and testing. The final design of Galeri Sulam Pinjaik Patah's visual identity has dynamic elements and flexible applications that allowed the gallery to improve and develop its visual identity.
\end{abstract}

Keywords: embroidery gallery, local wisdom, pinjaik patah, visual identity 


\section{PENDAHULUAN}

Sumatra Barat, tepatnya Nagari (Desa) Panampuang merupakan salah satu penggerak industri kreatif sulaman tradisional yang menjadi ikon nagari. Nagari Panampuang memiliki potensi yang besar dikarenakan hampir anggota tiap rumah tangga di Nagari Panampuang bergerak sebagai pengrajin sulaman. Nagari Panampuang ini terletak di Kecamatan Ampek Angkek, Kabupaten Agam, Sumatra Barat. Nagari adalah istilah yang digunakan di Sumatra Barat untuk penamaan desa, distrik, wilayah atau sekumpulan kampung dengan pemerintahan daerah yang kurang lebih sama dengan pemerintah desa (Vel \& Bedner, 2015; KBBI, 2016).

Nagari Panampuang terkenal sebagai nagari pinjaik patah. Hal ini disebabkan rata-rata perempuan di Nagari ini pandai menyulam. Untuk mempermudah proses menyulam maka jarum jahit (pinjaik) harus dipatah dua, lalu ujungnya akan di asah kembali sehingga jarum yang lebih pendek akan dengan mudah digerakan turun naik membentuk motif sulaman. Alat dan proses menyulam inilah yang membuat nagari Panampuang terkenal dengan sulaman pinjaik patahnya, yaitu penggunaan jarum jahit yang dipatahkan menjadi dua.

Kegiatan menyulam, alat serta proses menggunakan pinjaik patah ini sudah dilakukan oleh masyarakat Nagari Panampuang secara turun temurun. Ini merupakan potensi besar yang dimiliki oleh Nagari agar dapat menjadi penggerak utama pembangunan desa dan menjadi ikon wisata. Kegiatan menyulam yang awalnya dilakukan warga secara mandiri sekarang ditampung dalam sebuah wadah dibawah Badan Usaha Milik Nagari (BUMNAG) dalam bentuk Rumah Sulam.

Rumah sulam yang dinamakan dengan Galeri Sulam Pinjaik Patah merupakan usaha kolektif dengan tujuan untuk meningkatkan perekonomian warga dan menjadi ikon dan pusat sulam di Kabupaten Agam dan Sumatra Barat. Sebelum bisa dipromosikan menjadi salah satu ikon wisata dan kerajinan sulaman, Galeri ini membutuhkan sentuhan desain grafis berupa identitas visual agar sulaman Pinjaik Patah khas Nagari Panampuang bisa mendapatkan brand awareness, yaitu pemahaman konsumen mengenai suatu usaha atau produk (Xu, Li, \& Zhou, 2017) dan dikenal lebih luas. Desain grafis dapat berkontribusi dalam menegaskan dan mengkonstruksi secara positif identitas budaya yang dimiliki oleh suatu bangsa (Leitão \& Marchand, 2018)

Galeri sulam Pinjaik Patah saat ini sudah memiliki logo namun logo tersebut belum mencirikan sulaman pinjaik patah sebagai kearifan lokal Nagari Panampuang. Berdasarkan hasil Focus Group Discussion (FGD) perangkat galeri mengetahui bahwa logo yang ada belum mewakili identitas galeri sulam dengan baik dan sepakat untuk dibuatkan rancangan identitas visual yang sistematis dengan penggunaan yang konsisten. Logo sendiri hanyalah bagian dari sistem identitas visual (Alkibay, Ozdogan, \& Ermec, 2007). Logo layaknya nama seseorang hanyalah sebuah nama dan tidak memberikan gambaran mengenai kepribadian orang tersebut. Sedangkan identitas visual adalah cara suatu usaha untuk memperkenalkan dan membedakan entitasnya 
dengan yang lain melalui suatu sistem identitas dengan atribut lengkap dan penggunaan yang konsisten (Rustan, 2009; Newark, 2017).

Meskipun lebih kompleks, perancangan identitas visual dapat meningkatkan brand awareness sehingga target sasaran bisa memahami entitas sebagai suatu sistem utuh dan bukan hanya mengenal nama dan tampilan wajah saja. Dengan demikian, brand dari entitas bisa diingat oleh sasaran dalam jangka waktu yang lama. Perancangan identitas visual bertujuan meningkatkan brand awareness suatu usaha untuk kebutuhan internal bagi pemilik usaha dan pegawai (Bolhuis et al., 2015; Czekanski \& Lee, 2017) atau untuk rekognisi eksternal (Cosentino, 2015; Pratama \& Swasty, 2018) dan juga promosi (Darmawan \& Swasty, 2018; Yusantiar \& Soewardikoen, 2018). Namun, perancangan identitas visual galeri sulam Pinjaik Patah bertujuan untuk menciptakan brand image dan brand awarenes dan rekognisi bagi pemilik dan perangkat galeri dan bagi konsumen dengan menghadirkan sistem identitas visual yang konsisten dengan mengolah unsur budaya dalam tampilan modern yang lebih dinamis.

\section{METODE PENELITIAN}

Perancangan desain logo dan interior Galeri Sulaman Pinjaik Patah menggunakan metode Research and Development (R\&D). Metode ini digunakan untuk mendapatkan hasil produk yang baik dengan melewati berbagai tahapan termasuk didalamnya tahapan pengumpulan informasi, validasi dan uji coba produk (Sugiyono, 2018). Adapun tahapan dalam merancang produk menggunakan metode R\&D, yaitu:

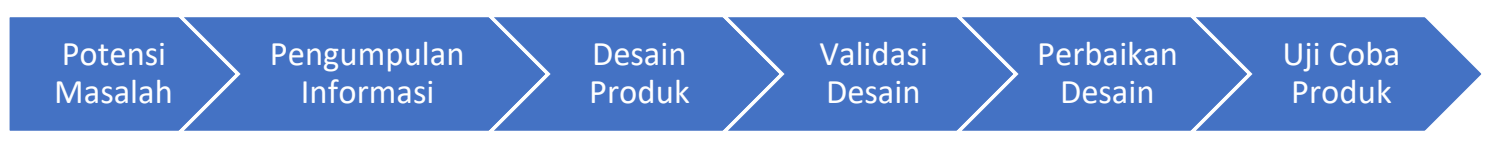

Gambar 1. Tahapan merancang produk menggunakan metode R\&D [Sumber: Diolah dari Sugiyono, 2018]

Tahap pertama adalah potensi dan masalah. Perancangan harus hadir karena adanya potensi dan masalah, dalam hal ini potensi dan masalah yang ada pada Galeri Sulam Pinjaik Patah. Galeri Sulaman memiliki potensi menjadi tempat destinasi jual beli produk sulaman di Sumatra Barat karena memiliki kekhasan terkait alat dan teknik sulam. Masalah yang timbul yaitu belum adanya sistem identitas visual yang baik untuk meningkatkan brand awareness audiens. Tahap kedua adalah mengumpulkan informasi. Tahapan ini dilakukan dalam bentuk Focus Group Discussion (FGD) dan didapatkan data antara lain mengenai profil dan latar belakang pendirian Galeri Sulam Pinjaik Patah. Hasil dari FGD dirangkum dalam sebuah rumusan Creative Brief yang kemudian menjadi dasar pemikiran dalam perancangan desain identitas visual. Dari data-data yang diperoleh didapatkan key benefit dan key value yang kemudian dikembangkan lagi menjadi keyword dalam merancang identitas visual.

Tahap ketiga yaitu desain produk. Pada tahapan ini dimulai dengan melakukan brainstorming dari rumusan creative brief. Hasil dari brainstorming didapatkan tiga keyword yang menjadi titik tolak rancangan identitas visual termasuk didalamnya rancangan picture mark, letter mark dan warna. Perancangan dimulai dengan membuat 
100 sketsa kasar yang kemudian dipilih menjadi lima, kemudian tiga dan terakhir dipilih menjadi satu untuk dibuat secara digital. Untuk pemilihan warna dan letter mark juga dilakukan tahapan yang sama. Tahap keempat adalah validasi desain. Tahapan validasi desain dilakukan secara terbatas, yaitu divalidasi oleh satu orang akademisi dan juga praktisi yang telah berpengalaman membuat desain grafis, brand, identitas visual, dan juga desain grafis untuk keperluan galeri.

Tahap kelima adalah perbaikan desain. Perbaikan desain diperlukan jika adanya saran dari hasil validasi desain. Terakhir tahap keenam adalah uji coba produk. Uji coba produk akan langsung dilakukan dengan ketua galeri dan anggota manajemen galeri. Pada tahapan ini akan dilihat pemahaman mitra terhadap identitas visual, kepuasan mitra terhadap identitas visual dan uji coba elemen identitas visual dalam media cetak.

Selain enam tahapan di atas, R\&D memiliki beberapa tahapan revisi produk hingga pembuatan massal. Namun, untuk perancangan ini baru sampai sejauh validasi, perbaikan dan uji coba produk. Tahapan mengumpulkan informasi adalah tahapan yang penting dalam mendesain. Tanpa memahami permasalahan yang ada dan tanpa memahami potensi yang dimiliki usaha secara mendalam justru akan membuat desainer kewalahan dalam merumuskan creative brief dan mendapatkan konsep desain.

\section{HASIL DAN PEMBAHASAN}

\subsection{Permasalahan yang Dihadapi}

Galeri sulam Pinjaik Patah sebagai tempat berkumpulnya pengrajin sulaman pinjaik patah yang dikelola oleh Badan Usaha Milik Nagari (BUMNag) telah memiliki logo. Hanya saja logo yang dimiliki belum merepresentasikan ciri khas dan kearifan lokal sulam pinjaik patah. Logo yang dimiliki baru berumur beberapa bulan. Sayangnya logo lama ini dibuat tanpa perencanaan yang matang. Seperti yang disampaikan oleh ketua galeri sulam Pinjaik Patah bahwa logo dirancang secara tergesa-gesa karena kebutuhan galeri untuk melakukan pameran di luar daerah sehingga perancangan logo tidak melalui tahapan perancangan yang baik seperti tahapan awal riset dan analisa mendalam.

Secara visual logo yang ada memiliki kelemahan. Logo lama merupakan penggabungan picture mark dan letter mark, yaitu gambar yang menyatu dalam tulisan. Sayangnya dalam penerapan logo pinjaik patah ini pemilihan desain ini membuat logo menjadi tidak dinamis. Bentuk picture mark berupa jarum (pinjaik) yang menggantikan huruf J dari nama Pinjaik terlihat dipaksakan dari segi ukuran. Secara keseluruhan logo belum mewakili kepribadian dari galeri sulam Pinjaik Patah.

Kesimpulan yang dapat ditarik dari permasalahan yang dihadapi entitas yaitu logo, baik secara tangible (fisik visual logo) dan intangible (pemahaman dan keterkaitan logo dan pemilik logo), belum mewakili kepribadian galeri sulam Pinjaik Patah sebagai suatu entitas usaha yang telah diwariskan secara turun temurun dan memiliki kearifan lokal di nagari tersebut. Logo ini perlu untuk diperbaiki segera agar entitas usaha dapat menggunakan desain logo yang mencirikan entitas usahanya. Perlu dilakukan riset awal 
mengenai entitas galeri sulam, produk sulaman yang mencari ciri khas nagari, dan stakeholder sebelum identitas visual yang baru dirancang.

\subsection{Pengumpulan Data melalui Focus Group Discussion}

Merancang identitas visual adalah kegiatan yang kompleks, dibutuhkan pemahaman yang mendalam mengenai usaha, permasalahan, tantangan, dan peluang yang dimiliki. Perancangan identitas visual Galeri Sulam Pinjaik Patah dimulai dari pengumpulan data melalui Focus Group Discussion (FGD). Hasil dari FGD dianalisa dan dirumuskan dalam bentuk creative brief sebagai pedoman dalam mendesain identitas visual.

Beberapa poin yang didapatkan dan dirumuskan dalam creative brief yaitu mengenai aspek kesejarahan, ciri khas dan nilai dari usaha sulaman ini bagi kehidupan masyarakat di Nagari Panampuang. Dari aspek kesejarahan, usaha sulaman sudah berlangsung secara turun temurun di masyarakat ini. Usaha ini awalnya dilakukan secara mandiri oleh anggota keluarga masyarakat panampuang, kemudian pada tahun 2018 dibuatlah Galeri Sulam sebagai badan usaha kolektif yang merupakan bagian dari koordinasi Badan Usaha Milik Nagari (BUMNag) Panampuang Saiyo dengan tujuan untuk meningkatkan perekonomian masyarakat sekitar.

Masyarakat pengrajin ini memiliki ungkapan "dek pinjaik patah ko lah kami bisa manyakolahan anak jadi sarjana", yang dapat diartikan sebagai "berkat (usaha sulaman) pinjaik patah ini kami dapat menyekolahkan anak menjadi sarjana (orang yang berhasil)". Disini bisa kita pahami bahwa selain memiliki aspek sejarah sebagai kerajinan turun temurun, usaha sulam pinjaik patah ini memiliki nilai yang kuat dalam masyarakat nagari ini. Sulaman pinjaik patah ini sudah menjadi bagian dari kehidupan mereka. Sehingga untuk identitas nama pinjaik patah pun sudah melekat di masyarakat nagari Panampuang itu sendiri atau masyarakat Sumatra Barat pemerhati kerajinan sulaman.

Adapun nama Pinjaik Patah ini berasal dari teknik menyulam yang merupakan ciri khas dari nagari Panampuang. Pinjaik patah (jarum jahit patah) mendapatkan namanya dari jarum jahit untuk sulam yang dipatahkan sehingga memiliki ukuran yang lebih pendek dari jarum jahit aslinya. Teknik dan alat yang menjadi ciri khas ini awalnya digunakan untuk memudahkan penyulam untuk menyulam kainnya. Jarum jahit pendek membuat kinerja penyulam pinjaik patah menjadi efektif dan efisien. Proses ini yang kemudian menjadi kearifan lokal, ciri khas dari masyarakat Nagari Panampuang. Hasil analisa yang didapatkan dari FGD dengan ketua galeri, ketua BUMNag dan masyarakat anggota galeri sulam disimpulkan dalam sebuah rumusan creative brief pada tabel 1. 
Tabel 1. Creative Brief Galeri Sulam Pinjaik Patah

[Sumber: Dokumentasi Penulis]

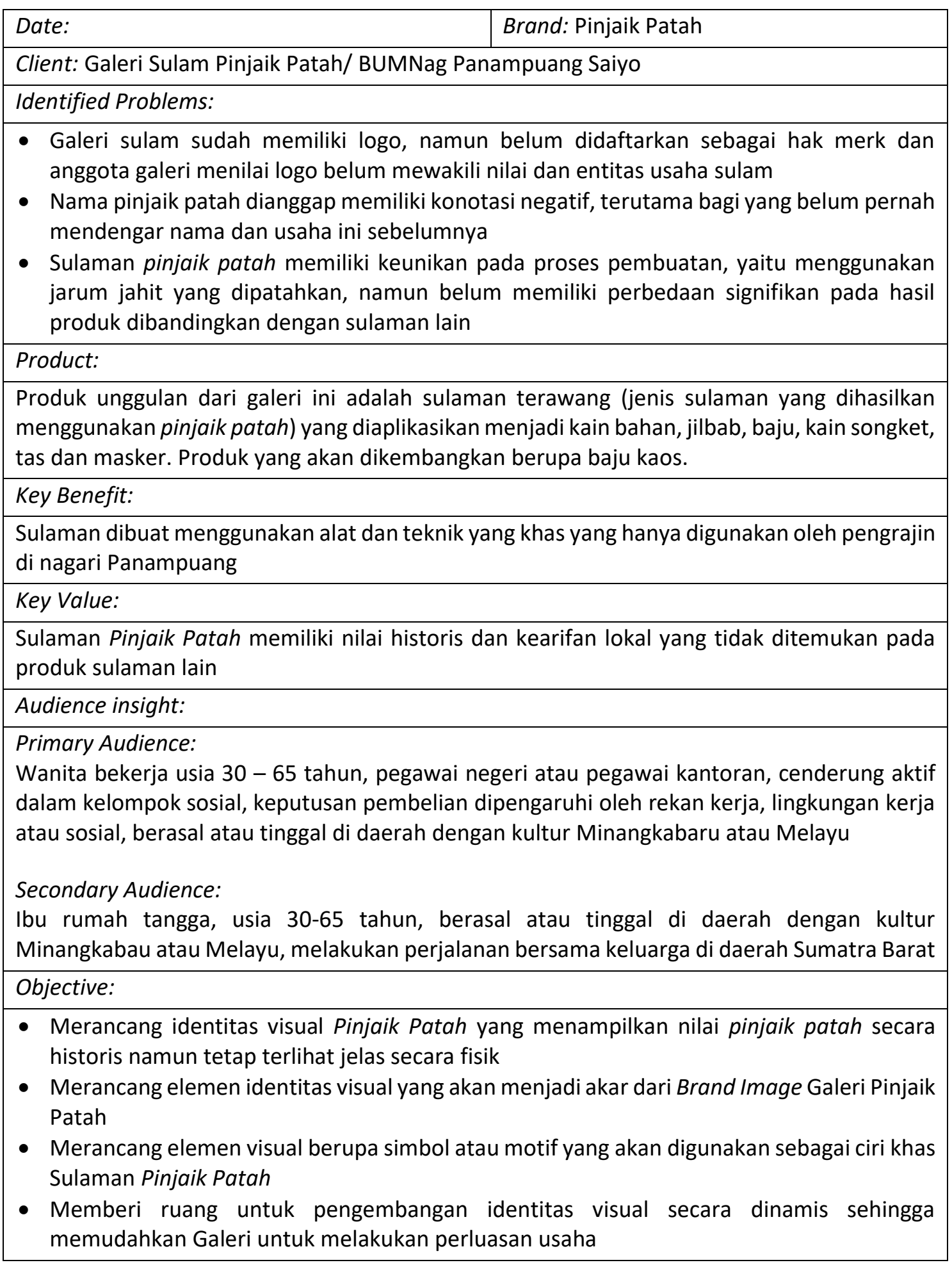

\subsection{Perancangan Identitas Visual}

Galeri Sulam Pinjaik Patah punya keunggulan yaitu ciri khas dari nama, alat dan teknik yang sudah digunakan beberapa generasi. Nama ini juga sudah dikenal oleh sebagian masyarakat di daerah Sumatra Barat, terutama masyarakat yang memerhatikan 
sulaman tradisi. Galeri Sulam ini sudah memiliki logo (gambar 2), yang baru berumur beberapa bulan yang digunakan untuk kepentingan promosi pada saat pameran kerajinan di Sumatra Utara. Meskipun demikian, perangkat Galeri Sulam merasa bahwa logo yang dimiliki belum mewakili brand image kearifan lokal pinjaik patah dan belum cukup dinamis untuk digunakan. Akan tetapi, mereka merasa bahwa identitas alat jahit tetap dimunculkan dalam identitas visual yang baru mengingat sulaman Pinjaik Patah ini adalah kehidupan mereka di nagari tersebut yang memiliki nilai sejarah dan kearifan lokal.

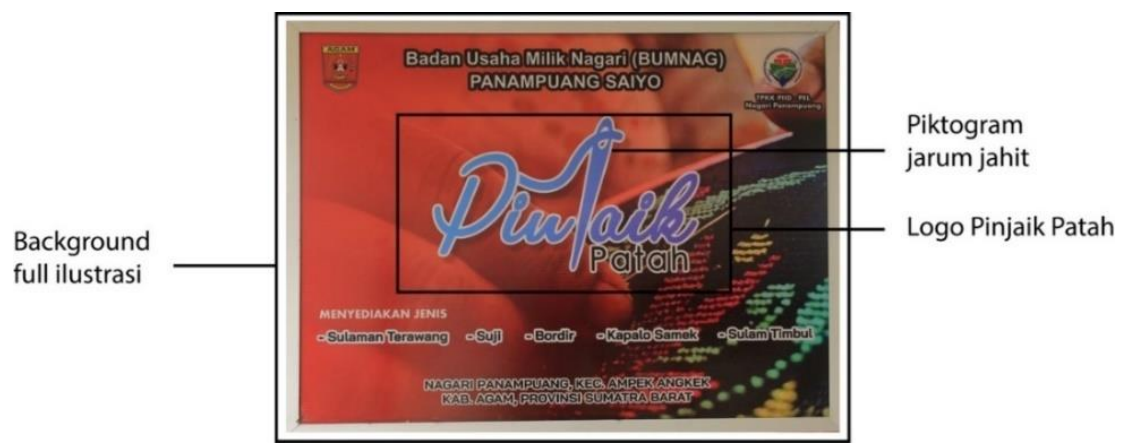

Gambar 2. Logo Awal Galeri Sulam Pinjaik Patah dalam Aplikasi Neon Box [Sumber: Dokumentasi Penulis]

Adapun beberapa elemen desain logo awal yang dianalisa terkait penggunaan pikitogram, tipografi, aplikasi pada media desain, dan logo secara keseluruhan. Berikut tabel hasil analisa yang dilakukan.

Tabel 2. Analisa Elemen Desain Logo

[Sumber: Dokumentasi Penulis]

\begin{tabular}{|l|l|}
\hline Elemen Desain & \multicolumn{1}{|c|}{ Keterangan } \\
\hline Piktogram & $\begin{array}{l}\text { Piktogram jarum jahit ditampilkan secara sederhana, mudah dipahami } \\
\text { bentuknya, tapi tidak mewakili jarum patah atau pinjaik patah sebagai alat } \\
\text { sulam dan nama merk Pinjaik Patah yang seharusnya memiliki ukuran lebih } \\
\text { pendek }\end{array}$ \\
\hline Tipografi & $\begin{array}{l}\text { Menggunakan dua typeface dengan klasifikasi berbeda, script dan sans serif. } \\
\text { Penggunaan kombinasi huruf dalam tipografi sebaiknya menggunakan } \\
\text { klasifikasi huruf dengan perbedaan yang cukup signifikan tapi tidak terlalu } \\
\text { menonjol (Seddon, 2015) }\end{array}$ \\
\hline Warna & $\begin{array}{l}\text { Warna antara tulisan pinjaik dan patah berbeda dan tidak menimbulkan } \\
\text { kesatuan. Warna kurang menonjol dan sulit diaplikasikan terutama pada } \\
\text { contoh neon box }\end{array}$ \\
\hline Desain Logo & $\begin{array}{l}\text { Latar belakang foto membuat logo tidak menonjol, tidak menjadi focal point } \\
\text { atau pusat perhatian. Logo harus diberi outline dan drop shadow agar } \\
\text { terlihat berbeda dengan latar belakang }\end{array}$ \\
$\begin{array}{l}\text { Proporsi piktogram jarum terutama dengan tulisan "patah" kurang baik. Ide } \\
\text { menggunakan dan menggantikan huruf J dengan piktogram jarum baik, } \\
\text { namun redundan. Tipe logo dengan penggunaan letter mark baik, namun } \\
\text { kurang dinamis dan tidak memberikan ruang untuk bermain dengan elemen } \\
\text { visual dan media desain }\end{array}$ \\
\hline
\end{tabular}


Hasil analisa logo awal memberikan beberapa kesimpulan untuk perancangan identitas visual baru. Identitas yang baru harus mengakomodir nilai sejarah dan kearifan lokal dari pinjaik patah, mewakili nama atau arti dari pinjaik patah, namun dinamis dengan menggunakan picture mark dan letter mark agar memberi ruang untuk eksplorasi elemen visual, bisa digunakan dalam bentuk yang konsisten dalam satu kesatuan sistem desain identitas visual.

\subsubsection{Picture Mark}

Berdasarkan analisa dan kesimpulan dari creative brief dan juga analisa terhadap logo awal maka didapatkan beberapa keyword untuk konsep perancangan identitas visual sebagai berikut: 1) pinjaik patah sebagai alat dan teknik sulam khas nagari Panampuang; 2) sumber kehidupan, dikarenakan usaha ini sudah menjadi sumber pendapatan bagi masyarakat nagari secara turun temurun; dan 3) pemersatu, dimana galeri sulam Pinjaik Patah ini menyatukan warga nagari yang awalnya hanya melakukan usaha sendiri sekarang dibantu menjadi usaha kolektif koordinasi dari BUMNag.

Perancangan identitas visual galeri sulam Pinjaik Patah ini dibagi menjadi beberapa bagian yaitu perancangan picture mark, perancangan letter mark, pemilihan warna, dan aplikasi elemen visual pendukung. Keseluruhan perancangan ini berangkat dari pengolahan keyword yang telah ditetapkan dan merujuk pada rumusan creative brief. Keputusan menggunakan gabungan picture mark dan letter mark dalam identitas visual dimaksudkan agar dalam penggunaannya bisa lebih dinamis. Masing-masing picture mark dan letter mark dapat digunakan secara bersamaan ataupun terpisah. Hal ini dapat membangun identitas visual dengan memperkenalkan elemen-elemen desainnya secara utuh ataupun terpisah.

Picture mark yang dirancang dibuat dalam piktogram sederhana agar mudah dikenali. Bentuk picture mark berangkat dari eksplorasi bentuk jarum jahit (pinjaik patah) yang dibuat menjadi bentuk geometris yang mempunyai 8 arah (gambar 3). Maksud dari 8 arah atau garis ini yaitu, 7 garis diantaranya merupakan representasi dari 7 Jorong yang ada di Nagari Panampuang. Sedangkan garis kedelapan yang dibuat dengan warna yang berbeda dan diletakkan di bagian atas hasil dari penyederhanaan bentuk jarum sebagai representasi dari pinjaik patah yang memiliki makna filosofis sebagai asal mula dan menjadi wujud pemersatu.

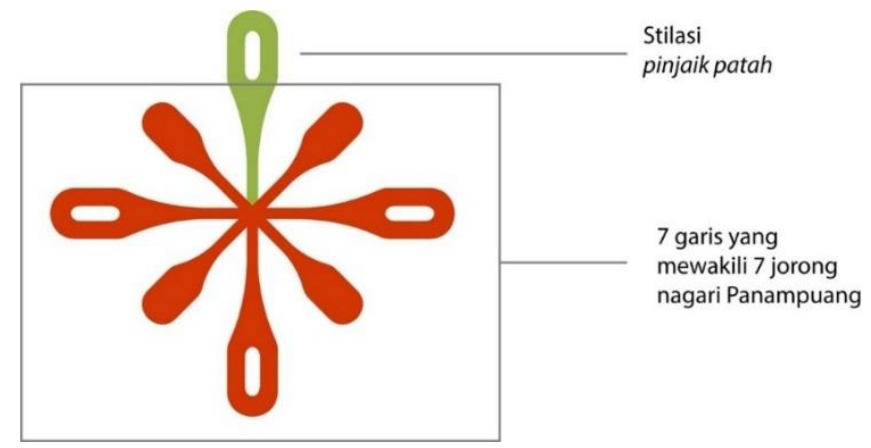

Gambar 3. Picture Mark Pinjaik Patah [Sumber: Dokumentasi Penulis] 
Rancangan picture mark dibuat dengan bentuk geometris karena berkaca pada beberapa motif-motif Minangkabau Sumatra Barat yang juga memiliki bentuk geometris. Bentuknya yang memusat ketengah merupakan representasi dari nilai pemersatu, bahwa galeri sulam Pinjaik Patah ini menjadi pemersatu masyarakat nagari Panampuang, bersama-sama memajukan kearifan lokal yang telah menunjang perekonomian masyarakat selama beberapa generasi. Bentuk geometri yang terdiri dari 8 bagian ini memiliki makna spiritualitas dan aktif (Cirlot, 2001). Empat bagian picture mark merupakan stilasi dari pinjaik patah, sedangkan empat bagian lainnya dibuat dengan ukuran lebih kecil dan tanpa lubang jarum. Ini semata adalah untuk memberikan aksentuasi agar picture mark tidak terlihat monoton.

Selain digunakan sebagai identitas visual, picture mark ini dapat dijadikan motif sebagai elemen visual pendukung. Mengingat nagari Panampuang dan galeri sulam Pinjaik Patah sejauh ini belum memiliki motif khas daerah Panampuang. Picture mark ini bisa diolah menjadi motif sulaman (gambar 4) dan juga bisa digunakan sebagai pengganti label baju untuk identitas pada produk. Penggunaan motif ini pastinya terbatas hanya bisa digunakan oleh galeri sulam Pinjaik Patah karena merupakan bagian dari identitas visualnya. Penggunaan motif baik dari warna ataupun penempatan bentuk fleksibel selama tidak merubah bentuk asli dari piktogram identitas visualnya.
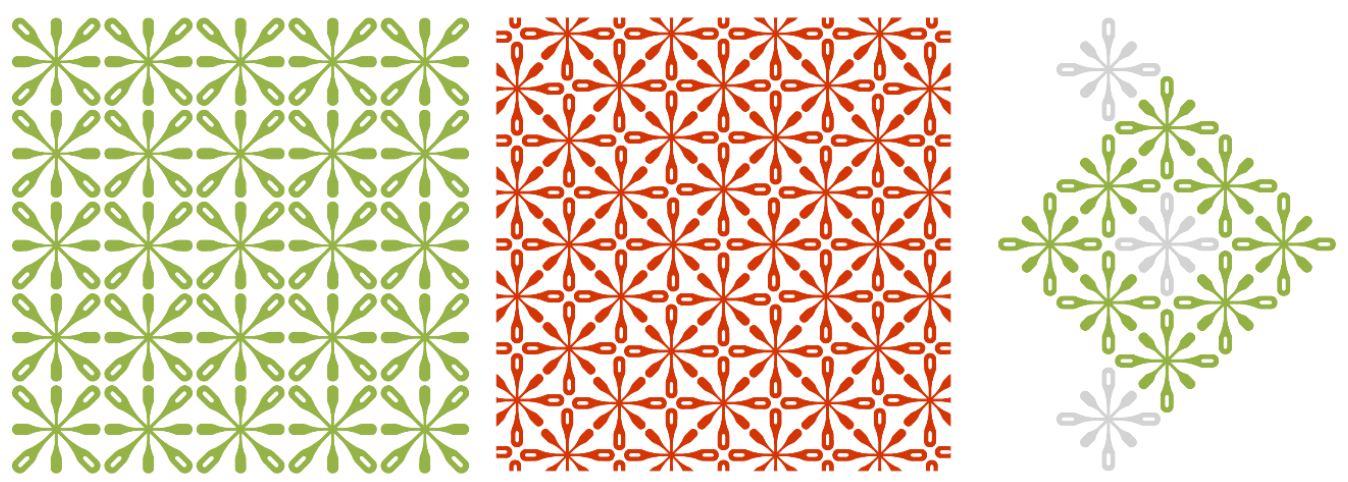

Gambar 4. Variasi penggunaan picture mark sebagai motif

[Sumber: Dokumentasi Penulis]

\subsubsection{Letter Mark}

Desain tipografi terutama dalam pemilihan typeface sangat berpengaruh terhadap pemahaman audiens, hal ini disebabkan karena typeface memiliki bentuk visual yang menghasilkan suatu makna (Jury, 2001). Typeface Raleway Semibold memiliki karakteristik yang rapi, proporsional dan sedikit kaku. Tujuan utama perancangan sistem identitas visual dengan menggunakan picture mark dan letter mark diharapkan menghasilkan bentuk dinamis dan dapat diterima oleh masyarakat sebagai tempat penghasil produk sulaman yang menarik dan terus berkembang seiring tuntutan zaman. Oleh sebab itu perlu adanya eksplorasi bentuk letter mark yang berangkat dari pengolahan typeface Raleway ini (Gambar 5). Eksplorasi typeface dilakukan agar letter mark yang dihasilkan orisinil dan dapat memiliki satu kesatuan bentuk bidangnya (shape) dengan eksplorasi bentuk picture mark. 


\section{PIN JAIK PATAH
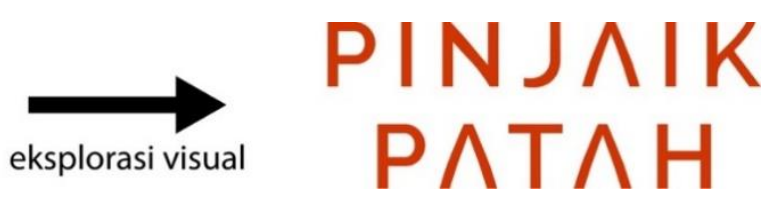

Gambar 5. Eksplorasi typeface

[Sumber: Dokumentasi Penulis]

Terdapat eksplorasi bentuk dari beberapa huruf dari nama Pinjaik Patah, yaitu pada huruf $\mathrm{N}, \mathrm{J}, \mathrm{A}$, dan K. Dasar perubahan bentuk dari beberapa huruf diatas diambil dari lengkungan yang ada pada picture mark. Tujuan perubahan ini yaitu untuk memberikan kesan unity antara picture mark dan letter mark, sehingga jika digunakan secara bersamaan atau terpisah masih tetap terlihat benang merah antara keduanya meskipun tidak begitu menonjol. Selain itu, perubahan dilakukan agar huruf dari typeface Raleway yang cukup kaku memiliki sedikit lengkungan yang memberi kesan berkarakter, budaya atau kearifan lokal. Ini juga mengingat bentuk motif yang digunakan dalam adat Minangkabau cenderung diambil dari bentuk organik seperti flora dan fauna yang memiliki garis lengkung dan tidak kaku. Hasil akhir dari perubahan bentuk tersebut membuat desain letter mark menjadi lebih dinamis.

Tabel 3. Eksplorasi bentuk visual letter mark

[Sumber: Dokumentasi Penulis]

\begin{tabular}{|c|c|c|c|}
\hline $\begin{array}{c}\text { Huruf typeface } \\
\text { Raleway }\end{array}$ & $\begin{array}{c}\text { Elemen desain } \\
\text { picture mark }\end{array}$ & $\begin{array}{c}\text { Perbandingan } \\
\text { before - after }\end{array}$ & Bentuk akhir \\
\hline & & & \\
\hline & & & \\
\hline
\end{tabular}


Empat huruf di atas diberi sentuhan lengkungan yang didasari dari bentuk-bentuk lengkungan dan sudut yang terbentuk dari elemen picture mark (gambar 3). Penambahan lengkungan pada beberapa bagian anatomi huruf membuat hasil akhir dari letter mark terlihat memiliki karakter budaya dan kearifan lokal. Sama seperti halnya picture mark, letter mark pun dapat digunakan tersendiri sebagai aplikasi identitas yang dinamis dan fleksibel. Eksplorasi bentuk typeface pun berguna agar terciptanya kesatuan unit tipografi. Typeface ini dapat digunakan untuk seluruh kebutuhan tipografi pada galeri sulaman Pinjaik Patah.

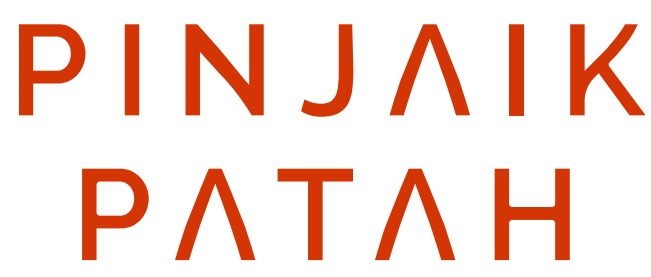

Gambar 6. Letter Mark

[Sumber: Dokumentasi Penulis]

\subsubsection{Warna}

Warna identitas visual didapatkan dari hasil studi berdasarkan keyword yang telah ditentukan sebelumnya. Adapun metode yang dilakukan yaitu dengan menuliskan kata kunci tersebut pada search engine Google dan melihat warna dominan yang muncul dari hasil pencarian tersebut. Warna yang muncul dari keyword sumber kehidupan dan pemersatu yaitu warna biru dan hijau yang muncul dari foto-foto alam. Selain itu keputusan elemen warna juga didasari dari kombinasi warna yang sering digunakan oleh pengrajin di galeri sulam Pinjaik Patah, yaitu warna hijau dan merah-orange.

Tabel 4. Elemen Warna

[Sumber: Dokumentasi Penulis]

\begin{tabular}{|c|c|l|l|}
\hline Warna & Kode warna & \multicolumn{1}{|c|}{ Psikologi warna } & \multicolumn{1}{|c|}{ Konsep Warna } \\
\hline D43504 & $\begin{array}{l}\text { Memiliki makna perayaan, } \\
\text { kekayaan, nasib baik, kuat, } \\
\text { energi, api, tenaga, menonjol }\end{array}$ & $\begin{array}{l}\text { Warna oranye merah } \\
\text { merupakan warna hangat } \\
\text { dan timeless. Warna ini } \\
\text { terlihat menonjol dan kuat }\end{array}$ \\
\hline 95 B346 & $\begin{array}{l}\text { Memiliki makna kecerdasan } \\
\text { tinggi, alam, musim semi, } \\
\text { kesuburan, masa muda, } \\
\text { lingkungan hidup, kekayaan, } \\
\text { rumput, keseimbangan, } \\
\text { kreatif, islam }\end{array}$ & $\begin{array}{l}\text { Pemilihan warna hijau } \\
\text { (cenderung hijau lumut } \\
\text { dengan hue yang lebih } \\
\text { dingin) adalah representasi } \\
\text { dari keyword pemersatu dan } \\
\text { sumber kehidupan yang } \\
\text { menjadi rumusan nilai dari } \\
\text { galeri sulam Pinjaik Patah. }\end{array}$ \\
\hline
\end{tabular}

Dalam mencari warna untuk mendapatkan kepribadian entitas dapat menggunakan tahapan sebagai berikut: 1) membuat daftar sifat, dalam perancangan logo Galeri sulaman didapatkan tiga keyword; 2) menentukan temperatur warna; 3) memilih 
kelompok hue; 4) memilih kelompok value; dan 5) melihat tingkat kontras (Rustan, 2019).

Pemilihan kombinasi warna oranye-merah dan hijau melalui proses brainstorming dengan menganalisa warna-warna representasi dari keyword sumber kehidupan. Selain itu juga dilakukan observasi pada warna-warna logo yang sering digunakan untuk usaha sejenis yaitu usaha kerajinan yang membawa nilai lokal. Pada umumnya warna yang digunakan pada logo sejenis yaitu warna kuning, coklat dan emas. Untuk menghindari warna yang umum, dan juga melihat dari representasi keyword yang dipilih maka elemen warna identitas visual galeri sulaman Pinjaik Patah dipilih menggunakan kombinasi warna merah dan hijau.

Kombinasi warna merah dan hijau yang dipilih memberi kesan lebih hidup dan memberikan keunikan dibandingkan entitas usaha sejenis yang cenderung menggunakan warna coklat, kuning dan emas. Hue yang muncul cenderung hangat dengan value warna tinggi (tint) atau cerah dan kontras yang tinggi. Meskipun galeri sulam Pinjaik Patah membawa nilai historis dan kearifan lokal, tetapi dengan menggunakan warna hijau dan merah membuat entitas ini menjadi lebih segar, dengan adanya pembaharuan-pembaharuan.

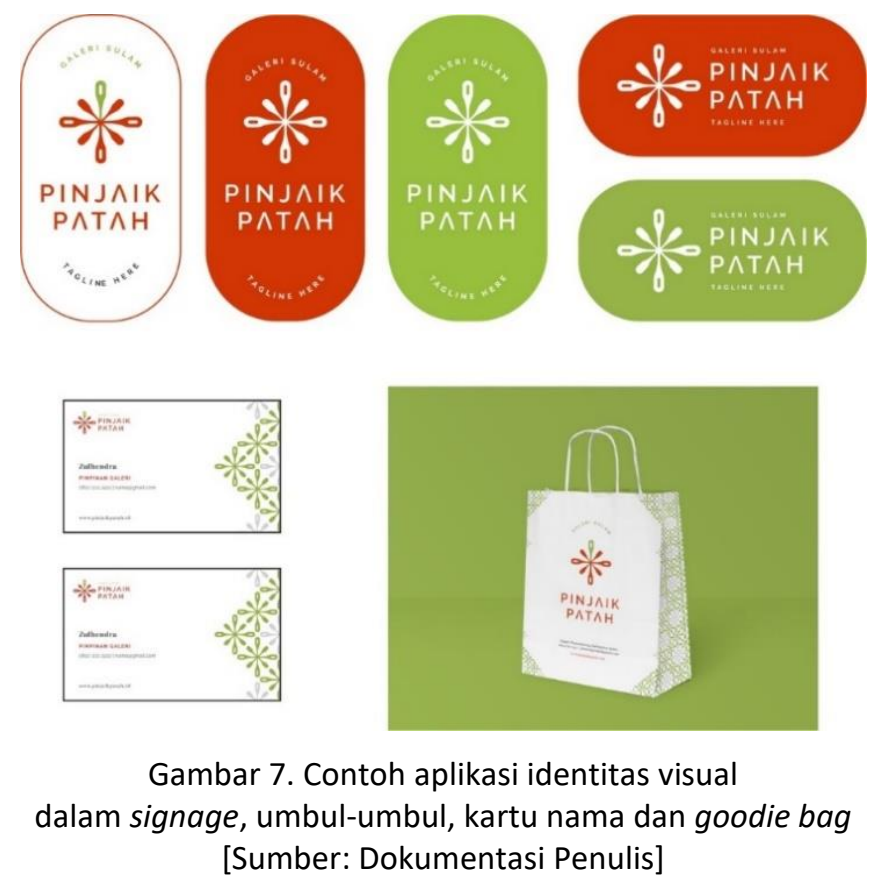

Identitas visual memberikan keleluasaan bagi pengguna desain untuk mengaplikasikan elemen-elemen desain yang ada secara dinamis tetapi masih dalam ketentuan yang ditetapkan. 


\subsection{Validasi Desain}

Hasil desain identititas visual diatas telah divalidasi oleh San Ahdi, selaku desainer grafis dan akademisi yang telah berpengalaman dalam membuat desain identitas visual. Validasi dilakukan dalam bentuk wawancara terbuka secara online. Poin-poin validasi yang diminta terkait dengan: 1) desain logo secara umum; 2) desain picture mark; 3) desain letter mark; 4) penggunaan warna. Dari validasi tersebut didapatkan hasil sebagai berikut pada tabel 5 .

Tabel 5. Validasi Desain

[Sumber: Dokumentasi Penulis]

\begin{tabular}{|l|l|}
\hline \multicolumn{1}{|c|}{ Poin Validasi } & \multicolumn{1}{c|}{ Penjelasan } \\
\hline Desain Logo & $\begin{array}{l}\text { Secara umum desain logo telah memenuhi aspek kriteria logo yang baik, } \\
\text { yaitu simplicity, clarity, dan balance. Selain itu desain logo yang dirancang } \\
\text { memiliki aspek keunikan. Secara sekeseluruhan desain logo mudah } \\
\text { dipahami, memiliki keterkaitan dengan bidang usaha/nama usaha; jelas } \\
\text { dan seimbang. Keunikan logo terlihat karena berbeda dari desain logo dari } \\
\text { usaha sejenis. Sehingga dari aspek-aspek yang disebutkan tadi, desain logo } \\
\text { akan mudah untuk dipahami dan diingat oleh audiens. }\end{array}$ \\
\hline Picture Mark & $\begin{array}{l}\text { Pemilihan ikon jarum jahit secara eksplisit membuat desain mudah } \\
\text { dimengerti. Bentuk picture mark bisa diartikan seperti bunga, arah, mata } \\
\text { angin dan juga bisa dimaknai sebagai suatu kekompakan. }\end{array}$ \\
\hline Letter Mark & $\begin{array}{l}\text { Font yang dipilih seirama dan senada dengan bentuk picture mark, } \\
\text { sehingga menciptakan suatu kesatuan (unity) dan keseimbangan (balance) } \\
\text { yang sempurna }\end{array}$ \\
\hline Warna & $\begin{array}{l}\text { Warna hijau memberi kesan harapan, tunas, potensi dan wilayah dengan } \\
\text { kombinasi warna yang unik }\end{array}$ \\
\hline
\end{tabular}

Setelah dilakukan validasi dengan praktisi sekaligus akademisi desain, selanjutnya diadakan FGD dengan mengumpulkan ketua galeri, ketua BUMNAG dan beberapa perangkat galeri. Pertemuan ini merupakan pertemuan untuk presentasi karya desain yang kemudian dilanjutkan dengan FGD. Hasil dari presentasi dan FGD yaitu desain identitas visual, baik dari bentuk picture mark, letter mark, pemilihan warna, dan penjelasan filosofis dibalik identitas visual tersebut diterima dengan sangat baik oleh pemangku dan perangkat galeri sulam Pinjaik Patah. Poin yang membuat klien tertarik pada identitas visual adalah kedinamisan identitas visual dimana picture mark dan letter mark dapat digunakan terpisah, adanya sistem penggunaan warna yang konsisten, serta bentuk piktogram picture mark yang dapat digunakan dan diolah menjadi motif sulaman.

\subsection{Perbaikan Desain}

Hasil desain identitas visual yang dirancang mendapatkan respon positif dari perangkat galeri. Respon positif yang diberikan antara lain mengenai desain identitas visual, makna logo, sistematika identitas visual dan rancangan stationery set. Hasil dari FGD tidak ada perbaikan desain, sehingga rancangan desain bisa segera diimplementasikan ke beberapa media. 


\subsection{Implementasi Desain}

Identitas visual yang telah dirancang diaplikasikan dalam berbagai media seperti plang nama, spanduk dan di media sosial. Konsistensi penggunaan identitas diperlukan dalam tahapan implementasi desain. Berikut adalah contoh penerapannya di plang nama.
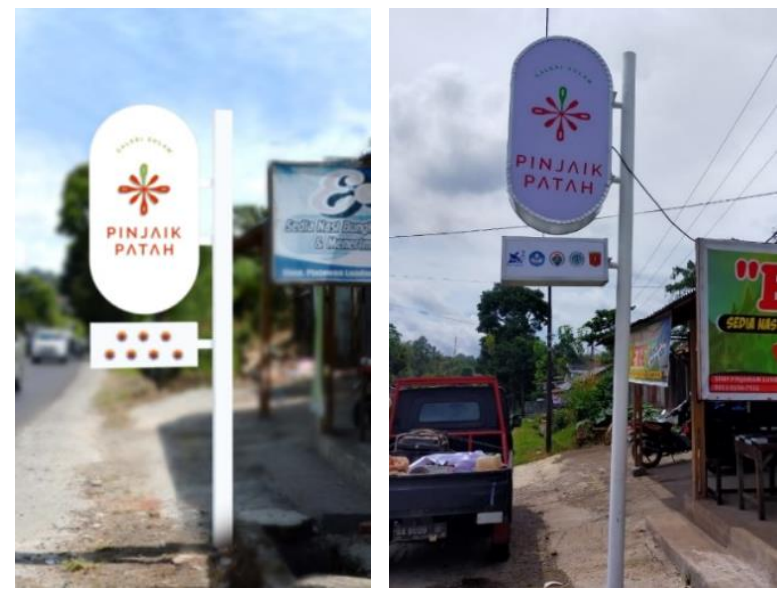

Gambar 8. (kiri) Desain 3D Mock-up, (kanan) Penerapan Logo pada Plang Nama [Sumber: Dokumentasi Penulis]

Implementasi desain yang telah dirancang ke media cetak perlu menjadi perhatian desainer grafis. Kemungkinan terjadinya kekurangan, kesalahan dalam pengaplikasian desain atau pengerjaan yang tidak rapi pada media cetak sangat mungkin terjadi. Final desain, desain mock-up dan real product bisa saja terlihat berbeda. Hal ini juga terjadi pada implementasi logo pada plang nama Pinjaik Patah dimana percetakan tidak mampu membuat desain dengan hasil yang rapi seperti yang diminta. Desainer perlu untuk memastikan bahwa mitra percetakan mampu membuat produk seperti rancangan yang diberikan. Kekurangan seperti ini lebih sering terjadi di daerah yang jauh dari ibukota. Contohnya pada implementasi desain logo pada plang nama Pinjaik Patah ini dimana percetakan tidak mampu membuat lengukangan pada plang nama dengan rapi. Tentunya kekurangan ini sangat disayangkan, apalagi jika kekurangan pada tahap implementasi desain sangat signifikan atau berupa kesalahan fatal. Kerjasama dan komunikasi antara desainer dan pihak percetakan sangat diperlukan.
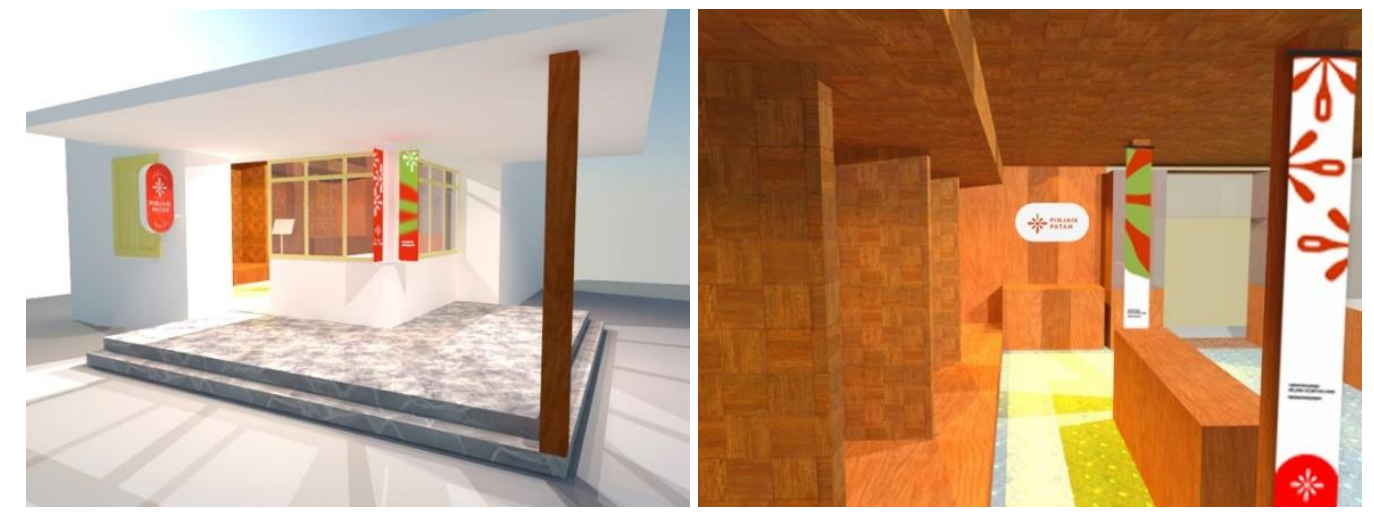

Gambar 9. (kiri) Penerapan Desain pada Eksterior Galeri, (kanan) Penerapan Desain pada Interior Galeri [Sumber: Dokumentasi Penulis] 
Gambar 9 merupakan rancangan 3D untuk penerapan desain pada interior dan eksterior galeri. Plang nama, dan desain banner menggunakan kombinasi warna yang telah ditetapkan pada rancangan identitas visual. logo utama adalah logo dengan warna dasar putih, namun pada plang nama eksterior bangunan dapat digunakan logo dengan warna merah. Meskipun penerapannya menggunakan warna yang berbeda tapi keseluruhan desain pada setiap media merupakan satu kesatuan sistem yang telah ditetapkan pada perancangan identitas visual. Jika diterapkan secara konsisten baik dari penerapan logo pada plang nama, banner, spanduk, umbul-umbul, stationery set dan merchandise maka akan terlihat kedinamisan desain.

\section{KESIMPULAN}

Identitas visual tidak hanya sekedar merancang logo, tampilan visual, untuk membedakan suatu entitas usaha dengan usaha lainnya. Tapi identitas visual mengatur bagaimana elemen-elemen desain tersebut digunakan secara sistematis dan konsisten namun masih memberikan peluang untuk digunakan secara dinamis. Identitas visual digunakan untuk penanda hak milik, dan sebagai media brand awareness. Merancang identitas visual yang baik harus dimulai dari memahami permasalahan di lapangan, salah satunya dengan mengadakan focus group discussion (FGD) bersama klien. Hasil FGD kemudian dianalisa dengan tim desain dan dirumuskan dalam creative brief sebagai acuan agar desainer masih berfikir dalam pokok permasalahan. Desainer perlu untuk melakukan tahapan validasi desain, baik kepada pakar, klien sebagai pengguna dan juga konsumen. Terakhir, pada tahapan implementasi desain, desainer harus memastikan bahwa pihak ketiga seperti mitra usaha cetak dapat membuat produk seperti yang telah dirancang.

Permasalahan desain grafis Galeri Sulam Pinjaik Patah tidak dapat diselesaikan hanya dengan logo saja, tapi dalam bentuk identitas visual. Penggunaan identitas visual yang terstruktur dan konsisten dapat menciptakan brand awareness mengenai pinjaik patah sebagai bagian dari kearifan lokal dan ikon wisata dan ikon produk sulaman di Sumatra Barat. Identitas visual yang dinamis dan penerapannya yang flesksibel dalam batas tertentu memberi ruang bagi pengguna identitas visual untuk melakukan eksplorasi terutama pada bagian piktogram picture mark yang dapat dimanfaatkan menjadi motif khas pinjaik patah nagari Panampuang.

\section{DAFTAR PUSTAKA}

Alkibay, D. S., Ozdogan, D. F. B., \& Ermec, A. (2007). Corporate Visual Identity: A Case in Hospitals. Health Marketing Quarterly, 24(3-4), 131-149.

Badan Pengembangan dan Pembinaan Bahasa. (2016). KBBI Daring. diakses 14 Desember 2020 https://kbbi.kemdikbud.go.id/entri/nagari

Bolhuis, W., Jong, M. D. T. De, Bosch, A. L. M. Van Den, Bolhuis, W., Jong, M. D. T. De, \& Bosch, A. L. M. Van Den. (2015). Corporate rebranding : effects of corporate visual identity changes on employees and consumers, 7266(November).

Cirlot, J.E. (2001). A Dictionary of Symbols. Second Edition. Taylor and Francis e-Library Cosentino, D. (2015). Designing the Identity of A New State: Kosovo Flag. The Design Journal, 18(4), 607-612. 
Czekanski, W. A., \& Lee, J. W. (2017). Journal for the Study of Sports and Athletes in Education Cock-a-Doodle-U : Examining University Brand Personality and Visual Identity at Coastal Carolina Cock-a-Doodle-U: Examining University Brand Personality. Journal for the Study of Sports and Athletes in Education, 7397(June), 1-17.

Darmawan, R. M. A., \& Swasty, W. (2018). Perancangan Ulang Logo dan Media Promosi CV. Kinandang Putera Sebagai Penguatan Identitas Visual. Andharupa, Jurnal Desain Komunikasi Visual Dan Multimedia, 4(2), 157-172.

Jury, David. (2017). What is Typography. Brighton: Ivy House

Leitão, R. M., \& Marchand, A. (2018). Graphic design as an instrument of identity assertion for indigenous peoples: the case of the Tapiskwan project. Communication Design, 7132, 1-21.

Newark, Quentin. (2017). What is Graphic Design. Brighton: Ivy Press

Pratama, F. D., \& Swasty, W. (2018). Logo dan Signage Sebagai Identitas Visual (Studi Kasus: Stadion Gelora Bandung Lautan Api). Andharupa, Jurnal Desain Komunikasi Visual Dan Multimedia, 4(2), 119-129.

Rustan, Surianto. (2011). Mendesain Logo. Jakarta: Gramedia

Rustan, Surianto. (2019). Warni: Buku 2. Jakarta: PT. Lintas Kreasi Imaji

Seddon, Tony. (2015). Type Teams: Perfect Typeface Combinations. London: Thames and Hudson

Sugiyono. (2018). Metode Penelitian Pendidikan (Pendekatan Kuantitatif, Kualitatif, $R \& D)$. Bandung: Alfabeta.

Vel, J. A. C., \& Bedner, A. W. (2015). Decentralisation and village governance in Indonesia : the return to the nagari and the 2014 Village Law, 9113(December).

Xu, F., Li, Y., \& Zhou, J. (2017). Brand Awareness for Entrepreneurial Hotel Chains: Perceived Quality and Brand Loyalty Brand Awareness for Entrepreneurial Hotel Chains : Perceived Quality and Brand Loyalty, 0073.

Yusantiar, R., \& Soewardikoen, D. W. (2018). Perancangan Identitas Visual untuk Promosi Pariwisata Kabupaten Rembang. Andharupa, Jurnal Desain Komunikasi Visual Dan Multimedia, 4(2), 207-220. 